\title{
Investigation of parameters that determine Nano-DC vaccine transport
}

\author{
Jingxin Zhang ${ }^{1,2}$. Junhua Mai ${ }^{1} \cdot$ Feng $\mathrm{Li}^{1,3}$. Jianliang Shen ${ }^{1,4} \cdot$ Guodong Zhang ${ }^{1}$ - Jun $\mathrm{Li}^{1,2} \cdot$ Louis E. Hinkle $^{1}$ • \\ Daniel Lin ${ }^{1} \cdot$ Xuewu Liu ${ }^{1} \cdot$ Zheng Li $^{3} \cdot$ Rong-fu Wang ${ }^{5}$. Elizabeth A Mittendorf ${ }^{6,7}$. Mauro Ferrari ${ }^{1,8} \cdot$ Haifa Shen ${ }^{1,9}$ (it)
}

Published online: 4 April 2019

(C) Springer Science+Business Media, LLC, part of Springer Nature 2019

\begin{abstract}
Effective migration of dendritic cells into the lymphatic system organs is the prerequisite for a functional dendritic cell vaccine. We have previously developed a porous silicon microparticle (PSM)-based therapeutic dendritic cell vaccine (Nano-DC vaccine) where PSM serves both as the vehicle for antigen peptides and an adjuvant. Here, we analyzed parameters that determined dendritic cell uptake of PSM particles and Nano-DC vaccine accumulation in lymphatic tissues in a murine model of HER2positive breast cancer. Our study revealed a positive correlation between sphericity of the PSM particles and their cellular uptake by circulating dendritic cells. In addition, the intravenously administered vaccines accumulated more in the spleens and inguinal lymph nodes, while the intradermally inoculated vaccines got enriched in the popliteal lymph nodes. Furthermore, mice with large tumors received more vaccines in the lymph nodes than those with small to medium size tumors. Information from this study will provide guidance on design and optimization of future therapeutic cancer vaccines.
\end{abstract}

Keywords Silicon $\cdot$ Microparticle $\cdot$ Nano-DC vaccine $\cdot$ Biodistribution $\cdot$ Transport

\section{Introduction}

Dendritic cell (DC) is the most powerful antigenpresenting cell (APC) in the body. DCs pick up tumor antigens and migrate to lymphatic tissues where they process the tumor antigen and present antigen epitopes to $\mathrm{T}$ cells, resulting in $\mathrm{T}$ cell activation. Based on the essential role of DCs in mediating anti-tumor immunity, dendritic cell vaccines have been developed to fight against human cancers. One peptide DC vaccine, sipuleucel-T, was approved by the US Food and Drug

Mauro Ferrari

mferrari@ houstonmethodist.org

Haifa Shen

hshen@houstonmethodist.org

1 Department of Nanomedicine, Houston Methodist Research Institute, Houston, TX 77030, USA

2 Xiangya Hospital of Central South University, Changsha 410000, Hunan, China

3 Center for Bioenergetics, Houston Methodist Research Institute, Houston, TX 77030, USA

4 State key laboratory of ophthalmology, School of Biomedical Engineering, Wenzhou Medical University, Wenzhou 325035, China
Administrations in 2010 for treatment of castrationresistant metastatic prostate cancers (Kantoff et al. 2010; Cheever and Higano 2011), and many dendritic cell vaccines are currently in various stages of clinical trials (Gelao et al. 2014; Carreno et al. 2015; Tanyi et al. 2018).

Since tumor antigen-pulsed DCs need to be properly activated in order for the DC vaccine to function properly, adjuvants are usually added into the vaccines to stimulate DC maturation. The most commonly used adjuvant in peptide DC vaccines is granulocyte-macrophage colony-stimulating

5 Center for Inflammation and Epigenetics, Houston Methodist Research Institute, Houston, TX 77030, USA

6 Department of Surgery, Brigham and Women's Hospital, Dana-Farber/ Brigham and Women's Cancer Center, Boston, MA 02115, USA

7 Breast Oncology Program, Dana-Farber/ Brigham and Women's Cancer Center, Boston, MA 02115, USA

8 Department of Medicine, Weill Cornell Medical College, 1300 York Avenue, New York, NY 10065, USA

9 Department of Cell and Developmental Biology, Weill Cornell Medical College, 1300 York Avenue, New York, NY 10065, USA 
factor (GM-CSF) (Knutson et al. 2001; Kantoff et al. 2010; Mittendorf et al. 2012; Tanyi et al. 2018). The Toll-like receptor ligands/agonists are also good candidates for vaccine development (Napolitani et al. 2005; Duthie et al. 2011). Various forms of nanoparticles have also been incorporated into different types vaccine forms to boost vaccine activity in recent years (Goldberg 2015). However, most DC vaccines have not met the expectation to potently fight against human cancers in clinic. Among the many factors that could negatively impact DC vaccine activity is the existence of physical and biological barriers that block effective migration of the cells into lymphatic organs (Shen et al. 2017). It has been estimated that less than $5 \%$ of total injected DCs can migrate out of the inoculation site, and the majority of the cells die in situ (Turnis et al. 2010). Thus, identification of parameters that dictate DC migration and cell entry into lymphatic tissues holds the key to generate effective therapeutic DC vaccines.

In an effort to develop effective treatment for human cancers, we have developed a porous silicon microparticle (PSM)-based DC vaccine (Nano-DC vaccine) (Xia et al. 2015). PSMs are biocompatible and water-soluble microparticles that have been successfully applied to deliver chemotherapy drugs and therapeutic small inhibitory RNA and microRNA molecules in our laboratories (Shen et al. 2013a, b; Xu et al. 2013; Mai et al. 2014; $\mathrm{Xu}$ et al. 2016; Zong et al. 2016; Ban et al. 2017). In the Nano-DC vaccine, PSM serves both as an adjuvant to stimulate TRIF/MAVS-dependent signaling and as a vehicle for packaging and sustained release of antigen peptides. A HER2 peptide-pulsed Nano-DC vaccine is effective in mediating anti-tumor immunity in murine models of HER2-positive breast cancer (Xia et al. 2015). In this study, we have examined correlation between physical parameters of the PSM and DC uptake of the particles. We have also analyzed impact from different routes of vaccination on Nano-DC vaccine accumulation in lymphatic tissues. Finally, we have compared Nano-DC vaccine enrichment in lymphatic tissues in mice with small, medium, and big size tumors. Our findings will be important for designing next-generation therapeutic DC vaccines.

\section{Materials and methods}

\subsection{Cells and cell culture}

TUBO cells were originally provided by Dr. Zen Wei (Wayne State University, Detroit, MI) and Guido Forni (University of Turin, Italy). Cells were cultured in DMEM medium supplemented with $10 \%$ fetal bovine serum (FBS) and $1 \%$ penicillin-streptomycin at $37{ }^{\circ} \mathrm{C}$ with $5 \% \mathrm{CO}_{2}$ and $95 \%$ humidity. Bone marrow cells were collected from the femurs and tibias of Balb/c mice and suspended in RPMI 1640 medium supplemented with $10 \%$ FBS and $1 \%$ penicillin-streptomycin. After cells were washed once with the medium, bone marrow cells were suspended in $1 \mathrm{ml}$ ACK lysing buffer for $1 \mathrm{~min}$. The suspension was then filtered using a sterile cell strainer $70 \mu \mathrm{m}$ Nylon mesh and centrifuged. Cells were resuspended in growth medium supplemented with $\beta$-mercaptoethanol, granulocyte-macrophage colony-stimulating factor (GM-CSF, $200 \mu \mathrm{g} / \mathrm{ml}$ ) and interleukin 4 (IL4, $200 \mu \mathrm{g} / \mathrm{ml}$ ) at a final concentration of $1 \times 10^{6}$ cells $/ \mathrm{ml}$, and seeded into 6 well plates $(4 \mathrm{ml}$ cell suspension per well). Cells were incubated at $37{ }^{\circ} \mathrm{C}$ with $5 \% \mathrm{CO}_{2}$ and $95 \%$ humidity for 7 days, and growth medium was changed every other day. On day 6, cells were stimulated with $100 \mathrm{ng} / \mathrm{ml}$ lipopolysaccharide (LPS). They were harvested on day 7, washed once, and resuspended in Opti-MEM medium at a concentration of $1 \times 10^{6}$ cells $/ \mathrm{ml}$.

\subsection{Nano-DC vaccine preparation}

Nano-DC vaccine was prepared following the same procedure as we have previously described (Xia et al. 2015). Briefly, the p66 HER2 peptide (TYVPANASL) was packaged into 1,2dioleoyl-sn-glycero-3-phosphocholine (DOPC) liposomes and the liposomes were subsequently loaded into the nanopores of PSM particles. The liposomal peptide-loaded PSM particles were then incubated with LPS-activated BMDCs.

\subsection{PSM for positron emission tomography/computed tomography (PET-CT) study}

PSM particles were produced by a combination of photolithography and electrochemical etching, and conjugated with APTES on surface to enhance stability in aqueous solution as previously described (Godin et al. 2012; Shen et al. 2012, 2013a). PSM images were taken with a JEOL JSM-7100F microscope (TouchScope). To prepare zirconium-89 labeled PSM ( ${ }^{89} \mathrm{Zr}$-PSM) for PET-CT study, PSM particles were first conjugated with deferoxamine (DFO) and then labeled with ${ }^{89} \mathrm{Zr}$. To prepare PSM particles for ${ }^{89} \mathrm{Zr}$ labeling, PSM suspension in dimethylformamide (DMF) were mixed with disuccinimidyl suberate (DSS, Thermo Fisher Scientific) and triethylene amine (TEA, Sigma-Aldrich), and the reaction was left for $30 \mathrm{~min}$ at room temperature. After washing twice with DMF, PSM particles were suspended in $1 \mathrm{ml}$ dimethyl sulfoxide (DMSO, Sigma-Aldrich) containing $20 \mu \mathrm{l} \mathrm{TEA}$ and $20 \mu \mathrm{l}$ DFO mesylate salt for $4 \mathrm{~h}$ at room temperature. Particles were washed twice and then vacuum dried. To label PSMs with ${ }^{89} \mathrm{Zr}, 1$ to 


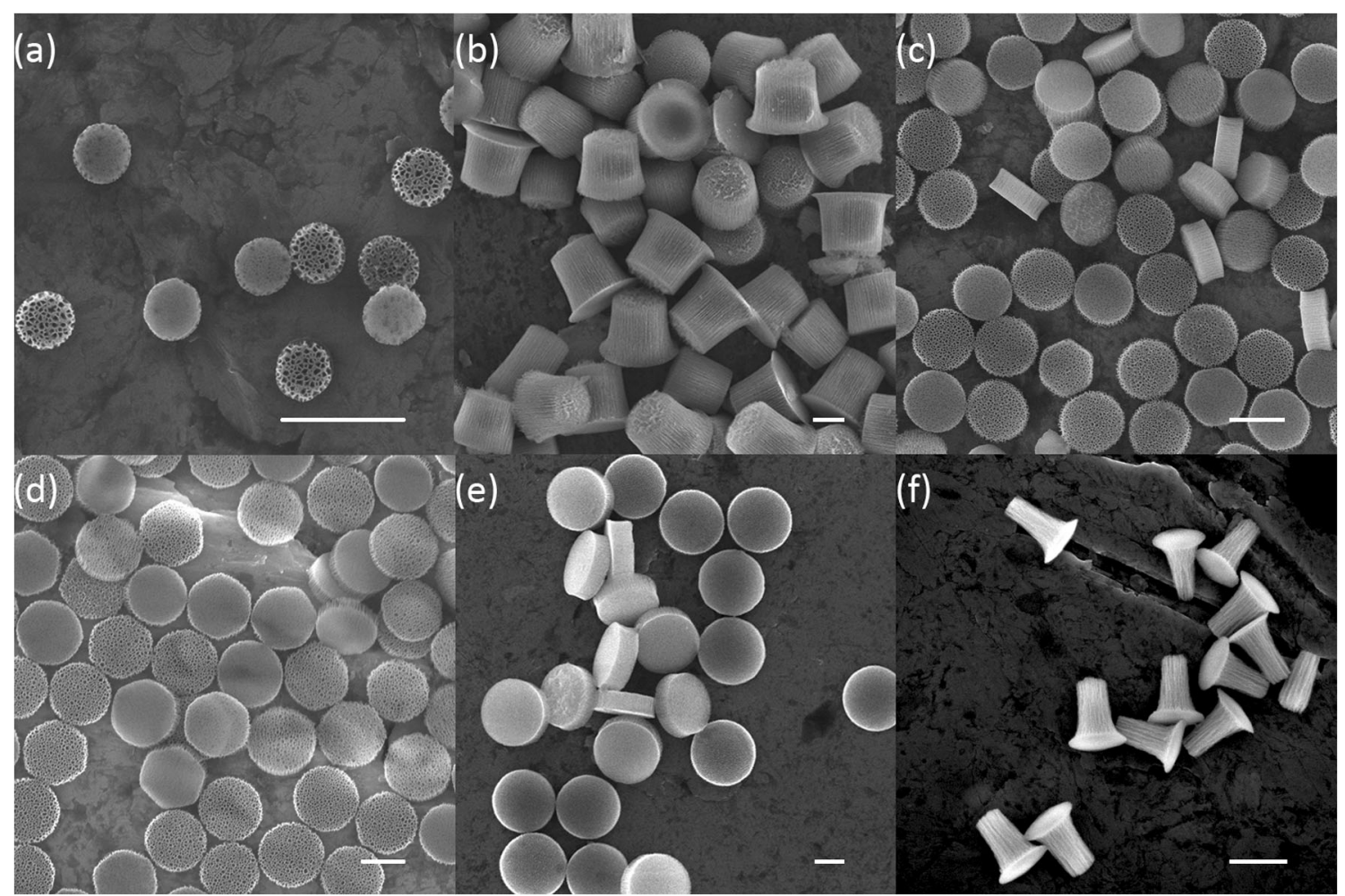

Fig. 1 SEM images of PSM particles with different size and shape. (a) $0.38 \mu \mathrm{m} \times 0.24 \mu \mathrm{m}$; (b) $1.64 \mu \mathrm{m} \times 1.76 \mu \mathrm{m}$; (c) $1 \mu \mathrm{m} \times 0.4 \mu \mathrm{m}$; (d) $1.5 \mu \mathrm{m} \times$ $0.4 \mu \mathrm{m}$; (e) $2.6 \mu \mathrm{m} \times 0.7 \mu \mathrm{m}$; (f) $0.88 \mu \mathrm{m} \times 1 \mu \mathrm{m}$. Scale bars: $1 \mu \mathrm{m}$

$4 \mathrm{mCi}{ }^{89} \mathrm{Zr}$-oxalate (Washington University, School of Medicine, Mallinckrodt Institute of Radiology) was added to the DFO-modified silicon particles. The suspension was mixed and sonicated for $1 \mathrm{~min}$, and then incubated at room temperature for $2 \mathrm{~h}$. The ${ }^{89} \mathrm{Zr}$ labeled PSMs were spinned down, and verified with a radio thin-layer chromatography TLC scanner (Bioscan AR2000).

\subsection{Flow cytometry analysis on particle uptake by circulating cells}

The following antibodies were used to stain single cells: antibodies for DC staining - anti-mouse CD45 (30-F11, Invitrogen), anti-mouse CD11b (M1/70, TONBO), anti-

Table 1 Zeta potential and sphericity of PSMs with different shapes and sizes

\begin{tabular}{lll}
\hline Size $(\mu \mathrm{m} \times \mu \mathrm{m})$ & Sphericity & Zeta potential \\
\hline $1.5 \times 0.4$ & 0.71 & $+6 \mathrm{mV}$ \\
$2.6 \times \mathrm{e} 0.7$ & 0.71 & $+6 \mathrm{mV}$ \\
$1 \times 0.4$ & 0.79 & $+6 \mathrm{mV}$ \\
$0.4 \times 0.2$ & 0.85 & $+6 \mathrm{mV}$ \\
$0.9 \times 1$ & 0.86 & $+5 \mathrm{mV}$ \\
$1.6 \times 1.7$ & 0.87 & $+6 \mathrm{mV}$ \\
\hline
\end{tabular}

mouse CD11c (N418, TONBO), and anti-mouse MHC II (AF6-120.1, eBioscience), anti-mouse CD115 (T38-320, BD), and anti-mouse Ly-6G (RB6-8C5, eBioscience). After incubation, the antibody/cell mixtures were left on ice for $30 \mathrm{~min}$. The cells were then washed 3 times with $1 \mathrm{ml} \mathrm{2 \%} \mathrm{FBS}$ in PBS, and centrifuged at $300 \times \mathrm{g}$ for $3 \mathrm{~min}$. Cells were resuspended in $300 \mu \mathrm{l} 2 \% \mathrm{FBS}$ in PBS, and separated with flow cytometry using the LSR II (BD Biosciences) for the $\mathrm{CD} 45^{+} \mathrm{CD} 11 \mathrm{~b}^{+} \mathrm{CD} 11 \mathrm{c}^{+} \mathrm{MHCII}{ }^{+}$ $\mathrm{DCs}, \mathrm{CD} 45^{+} \mathrm{CD} 11 \mathrm{~b}^{+} \mathrm{CD} 115^{+}$macrophages, and $\mathrm{CD} 45^{+} \mathrm{CD} 11 \mathrm{~b}^{+} \mathrm{Ly}-6 \mathrm{G}^{+}$neutrophils. Results were analyzed with FACSDiva (BD Biosciences).

\subsection{Animal studies}

All animal procedures were approved by Houston Methodist Research Institute IACUC. Balb/c mice were purchased from the Jackson Laboratory or Charles River. To test particle uptake by circulating cells, mice were treated in the foot pads (i.d.) with PSM particles of different size and shape, and blood samples were collected 30 min later for flow cytometry. To examine biodistribution of Nano-DC vaccines, 6 to 8 -weekold female Balb/c mice were inoculated with TUBO cells $(5 \times$ $10^{5}$ cells/mouse in phosphate buffer saline (PBS)/Matrigel) in the mammary fat pads. The tumor-bearing mice were treated i.d. or intravenously (i.v.) with vaccines, and imaged using PET-CT at different time points. Mice were sacrificed after 
(a)

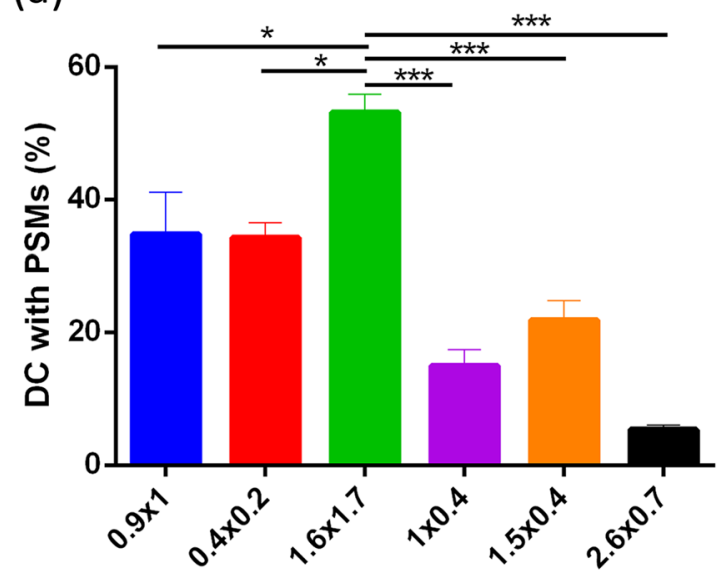

(c)

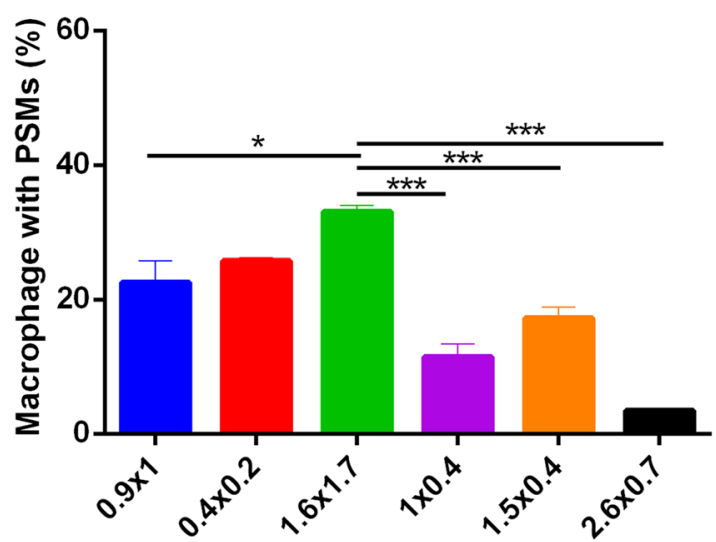

Fig. 2 Internalization of PSMs by dendritic cells, neutrophils, and monocytes. (a-c) Flow cytometry analysis on percentage of DCs, neutrophils, and monocytes internalized with PSMs in popliteal lymph nodes from vaccinated mice $(n=5)$ after i.d. injection. Data is presented as mean \pm SEM. $* p<0.05, * * p<0.01, * * * p<0.001$. (d) Correlation

PET-CT imaging, and major organs, and tumors and lymph nodes were collected and processed for flow cytometry or radioactivity measurement.

\subsection{Statistical analyses}

Statistical significance between 2 test groups was analyzed using Student's $t$ test. One-way ANOVA was applied to compare statistical significance among multiple groups.

\section{Results}

\subsection{Characterization of PSMs}

Six groups of PSMs were applied to evaluate particle uptake by phagocytic cells in circulation including DCs, monocytes (b)

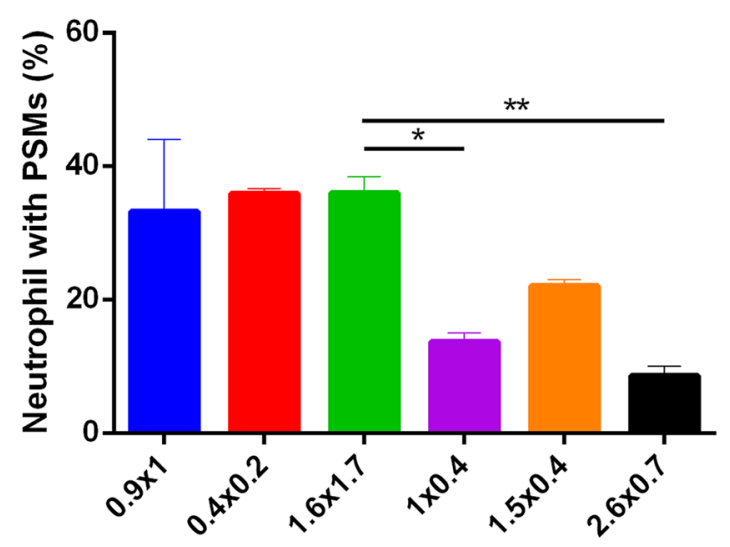

(d)

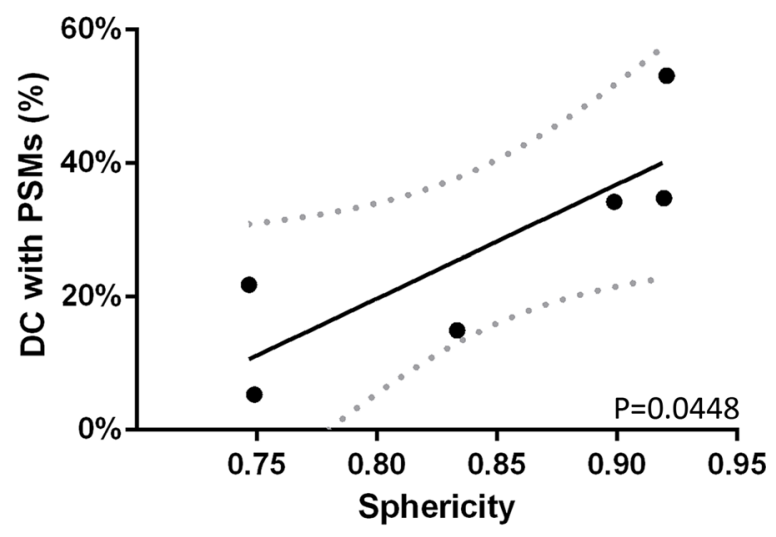

between percentage of PSM internalization by DCs and particle sphericity. Sphericity is calculated by $\Psi=\frac{\pi^{\frac{1}{3}}(6 \mathrm{~V})^{\frac{2}{3}}}{A}$, where $\mathrm{V}$ is the volume and $\mathrm{A}$ is surface area of the particle

and neutrophils in vivo. Although they differed by size and shape (Fig. 1a-f), all particles contained nanometer-size pores that could be loaded with antigen peptides. In addition, PSMs were chemically modified on surface with APTES and subsequently conjugated with the cyanine 5 (Cy5) fluorescent dye for imaging and detection. Detailed parameters of the particles are summarized in Table 1.

\subsection{Physical properties of PSM on particle uptake efficiency by circulating phagocytic cells}

Since Nano-DC vaccine was prepared by incubating antigen peptide-loaded PSM particles with BMDCs and there was a possibility that the particles could be passed to other cells in vivo (Xia et al. 2015), we evaluated uptake by DCs and other cell types after the same number of Cy5-labeled PSMs were administered in the foot pads of BALB/c immuno- 
(a)

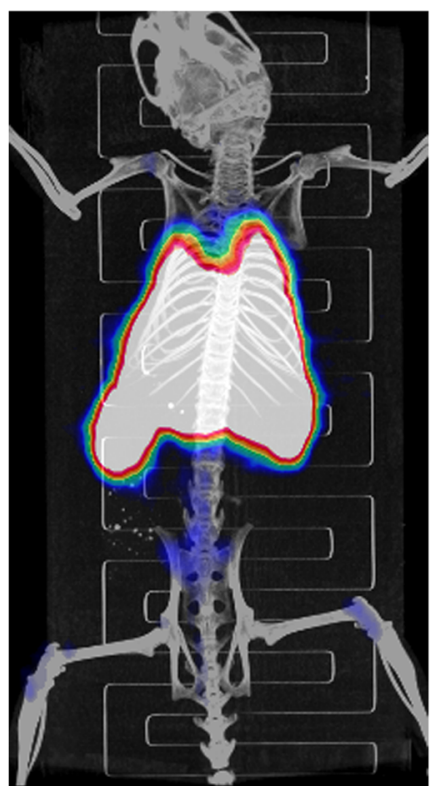

(c)

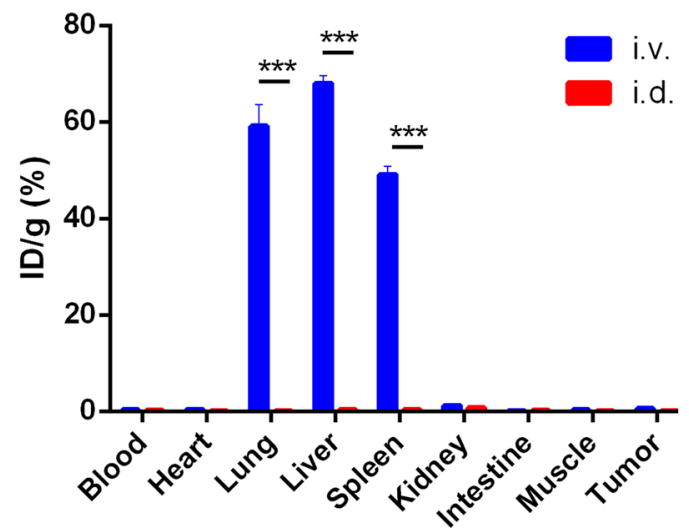

Fig. 3 Biodistribution of Nano-DC vaccine in major organs and lymph nodes after $i . v$. and $i . d$. inoculation. (a-b) PET-CT images of mice $24 \mathrm{~h}$ after vaccination by $i . v$. and $i . d$., respectively. (c-d)

competent mice. Flow cytometry was applied to determine percentage of Cy5-positive cells. Interestingly, the six types of particles could be assigned into two groups based on their uptake by DCs, macrophages and neutrophils. Specifically, mice treated with $0.9 \times 1 \mu \mathrm{m}, 0.4 \times$ $0.2 \mu \mathrm{m}$, and $1.6 \times 1.7 \mu \mathrm{m}$ particles had higher levels of particle uptake by all three cell types than those treated with $1 \times 0.4 \mu \mathrm{m}, 1.5 \times 0.4 \mu \mathrm{m}$, and $2.6 \times 0.7 \mu \mathrm{m}$ particles (Fig. 2a-c). The highest DC uptake rate was detected in mice treated with the $1.6 \times 1.7 \mu \mathrm{m}$ particles. A positive correlation was established between sphericity of the particles and cellular uptake (Fig. 2d). Based on this result, we concluded that particle sphericity, but not particle size, that determined particle uptake by the phagocytic cells in vivo. Thus, the $1.6 \times 1.7 \mu \mathrm{m}$ particles were selected for further analysis in the study. (b)

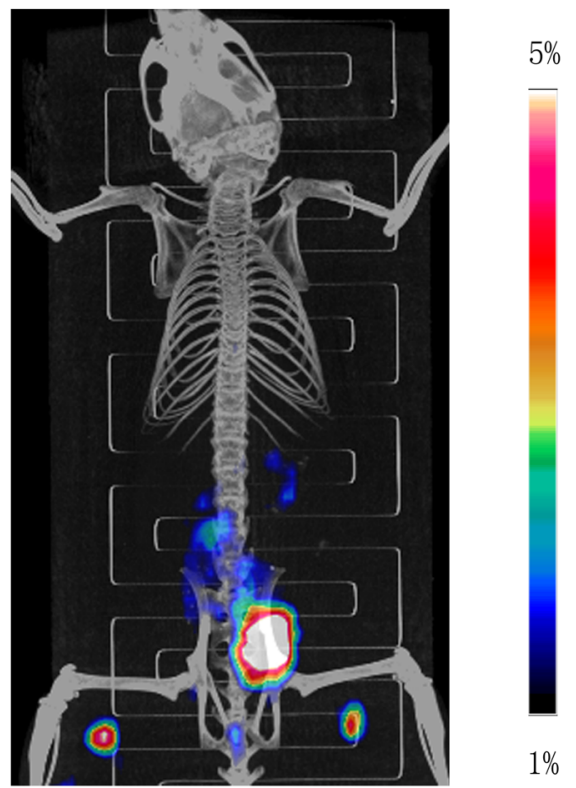

(d)

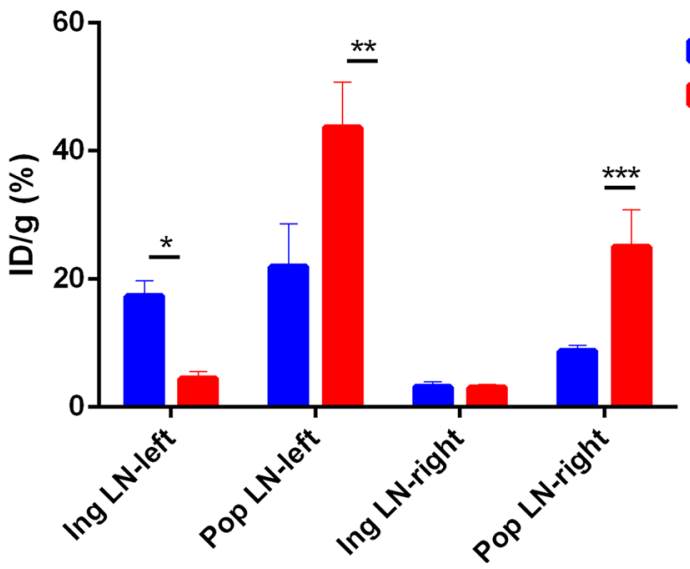

Accumulation of radioactive Nano-DC vaccine in major organs and lymph nodes $24 \mathrm{~h}$ after vaccination. $\mathrm{Y}$ axis is presented by counts per injection dosage per gram $(n=3)$

\subsection{Route of vaccination-dependent biodistribution of Nano-DC vaccines}

In a previous study, we developed a Nano-DC vaccine contained a HER2-specific antigen peptide, and applied the vaccine to treat mice with primary HER2-positive TUBO tumors (Xia et al. 2015). The TUBO tumor line was originally derived from a mammary gland tumor in a BLAB/c mouse carrying an MMTV-HER2 transgenic gene (Lucchini et al. 1992). In order to track Nano-DC vaccine migration inside the body, we labeled PSMs with ${ }^{89} \mathrm{Zr}$ before they were used to assemble the vaccine. Mice with primary TUBO tumors were treated with an equal amount of Nano-DC vaccine (normalized by radioactivity) either by tail vein injection (i.v.) or intra-footpad injection (i.d.). PET-CT was performed 3, 6, and $24 \mathrm{~h}$ after vaccination to monitor time-dependent vaccine 
migration. Mice were euthanized at the 24-h time point, and major organs and lymph nodes were collected to quantitatively measure radioactivity. As expected, the intravenously inoculated vaccines mainly accumulated in the major organs, while the intra-footpad injected vaccines slowly migrated through the draining lymph nodes, i.e., the popliteal lymph nodes (Fig. 3a-b), resulting in major differences on biodistribution in the liver, lung and spleen (Fig. 3c). Both routes of vaccination could lead to accumulation of NanoDC vaccine in the lymph nodes, although there was a trend of asymmetrical distribution pattern, with the left side lymph nodes consistently accumulating higher number of ${ }^{89} \mathrm{Zr}$-labeled Nano-DC vaccines than those on the right side (Fig. 3d).

\subsection{Correlation between tumor size and biodistribution of Nano-DC vaccine}

Correlation between tumor size and Nano-DC vaccine biodistribution was studies in mice with small $\left(200 \mathrm{~mm}^{3}\right)$, medium $\left(500 \mathrm{~mm}^{3}\right)$, and large $\left(1000 \mathrm{~mm}^{3}\right)$ size primary

(a)

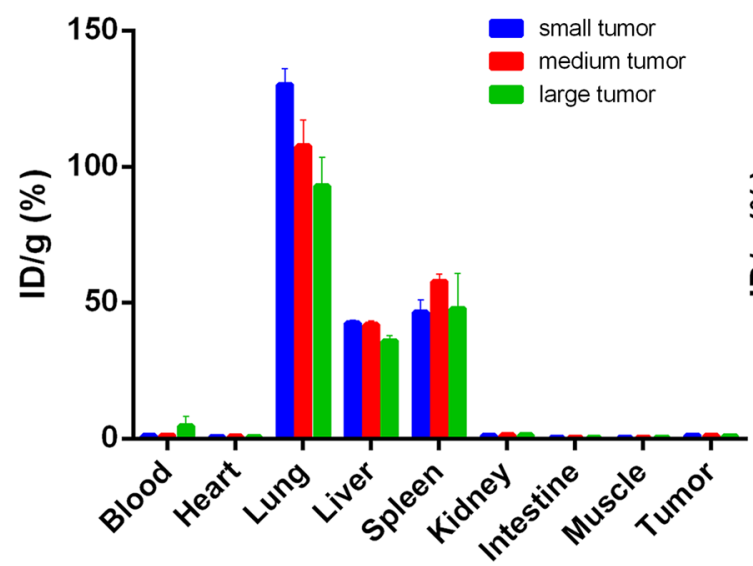

(c)

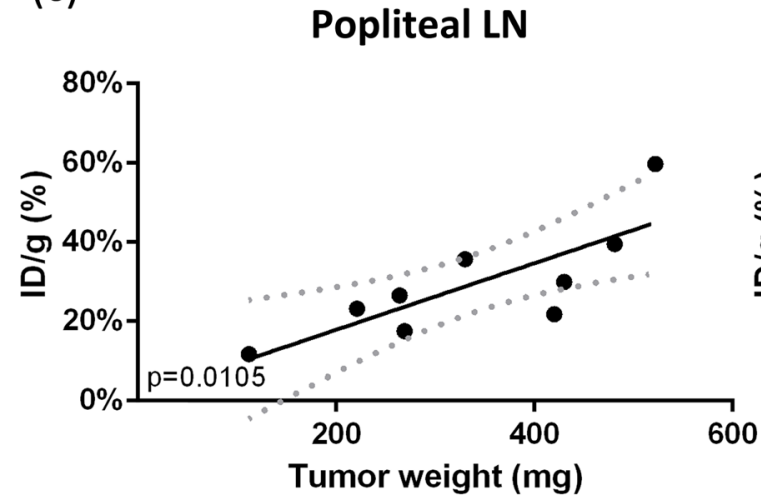

Fig. 4 Biodistribution of intravenously inoculated Nano-DC vaccine in mice with different size tumors. (a) Accumulation of Nano-DC vaccine in major organs in mice with different size tumors $24 \mathrm{~h}$ after
TUBO tumors. Mice were treated with ${ }^{89} \mathrm{Zr}$-labeled NanoDC vaccines by i.v. injection, and major organs and lymph nodes were collected $24 \mathrm{~h}$ later to measure radioactivity. While no statistical significance was obtained in the liver, lung, or spleen (Fig. 4a), more Nano-DC vaccine accumulated in the left popliteal and inguinal lymph nodes in mice with large-size tumors over those with small and medium size tumors (Fig. 4b). In both inguinal and popliteal lymph nodes, we observed asymmetric accumulation of the Nano-DC vaccine, with lymph nodes on the left side receiving more Nano-DC vaccine than those on the right side (Fig. 4b). Quantitative analysis revealed a positive correlation between tumor weight and Nano-DC vaccine accumulation in the popliteal lymph nodes (Fig. 4c), but not in the inguinal lymph nodes (Fig. 4d).

\section{Discussion and conclusion}

Nanotechnology has been increasing applied in cancer immunotherapy (Goldberg 2015; Shen et al. 2017). Various types of

(b)

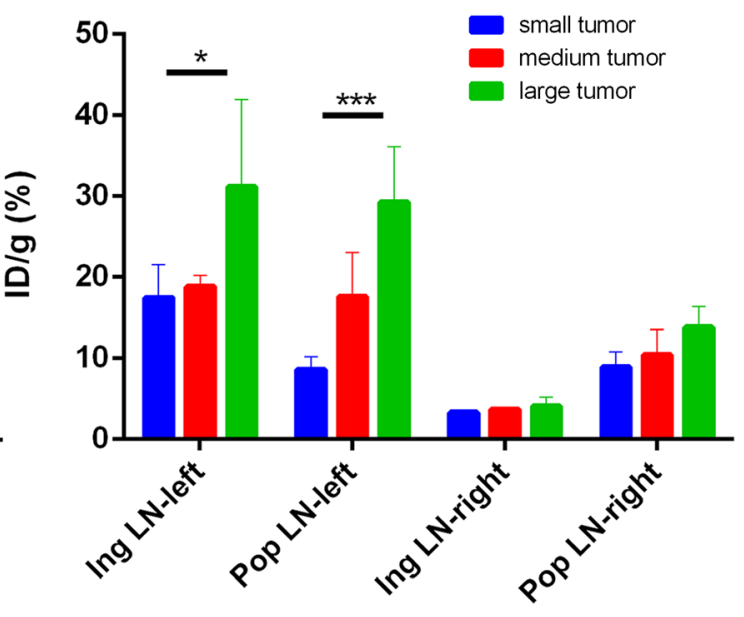

(d)

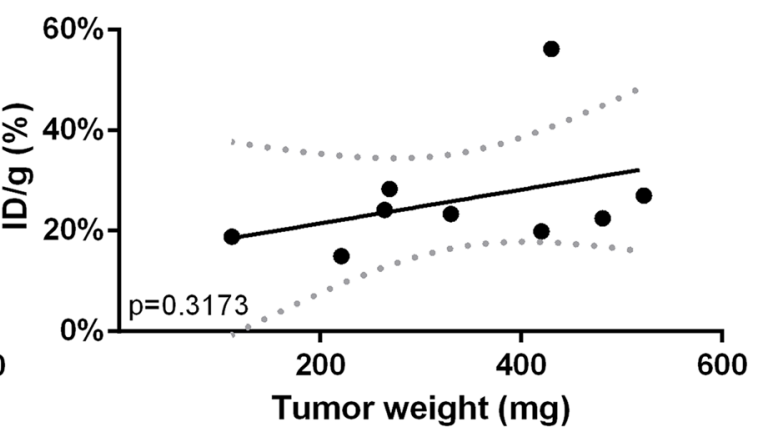

vaccination $(\mathrm{n}=3)$. (b-d) Correlation between tumor weight $(\mathrm{mg})$ and Nano-DC vaccine accumulation in tumors and lymph node. $\mathrm{Y}$ axis is presented by count cper injection dosage per gram 
nanoparticles with different physicochemical properties have been used ranging from inorganic mesoporous silica ( $\mathrm{Li}$ et al. 2018) to polymeric nanoparticles (Luo et al. 2017) to hybrid nanodiscs (Kuai et al. 2017). Regardless the type, all nanometer-scale particles need to interact with the immune cells in order to exert their biological activities. It is thus important to understand the parameters that are required for effective particle uptake by the APCs.

It has been reported that physical properties of the antigencarrying particles can dictate the type of immune responses (Kumar et al. 2015). In our study, we have applied particles in the nanometer to micrometer range to carry tumor antigens and demonstrated that the overall shape of the PSM particles is a key parameter to determine uptake by DCs and macrophages, two of the major APC populations. We have also found that different routes of vaccination can drastically alter the distribution pattern of Nano-DC vaccine in the spleen and major lymph nodes. Interestingly, we detected an asymmetric distribution pattern of Nano-DC vaccines in the tumor-bearing mice. There have been reports on asymmetric distribution of lymph nodes (Ghezzi et al. 2006; Yoruk et al. 2014). It remains to be determined whether asymmetric distribution of Nano-DC vaccine is a result of the asymmetric pattern of lymph nodes.

Overall, information generated from our study will provide guidance on design of future particulate cancer vaccines for effective uptake by the APCs in order to achieve optimal antitumor immunity.

Acknowledgements This work was partially supported by National Institutes of Health grants R01CA193880, R01CA222959 and U54CA210181, US Department of Defense grant W81XWH-17-10389, and METAvivor.

\section{References}

Y. Ban, J. Mai, X. Li, M. Mitchell-Flack, T. Zhang, L. Zhang, L. Chouchane, M. Ferrari, H. Shen, X. Ma, Targeting autocrine CCL5-CCR5 Axis reprograms immunosuppressive myeloid cells and reinvigorates antitumor immunity. Cancer Res. 77(11), 28572868 (2017)

B.M. Carreno, V. Magrini, M. Becker-Hapak, S. Kaabinejadian, J. Hundal, A.A. Petti, A. Ly, W.R. Lie, W.H. Hildebrand, E.R. Mardis, G.P. Linette, Cancer immunotherapy. A dendritic cell vaccine increases the breadth and diversity of melanoma neoantigenspecific T cells. Science 348(6236), 803-808 (2015)

M.A. Cheever, C.S. Higano, PROVENGE (Sipuleucel-T) in prostate cancer: The first FDA-approved therapeutic cancer vaccine. Clin. Cancer Res. 17(11), 3520-3526 (2011)

M.S. Duthie, H.P. Windish, C.B. Fox, S.G. Reed, Use of defined TLR ligands as adjuvants within human vaccines. Immunol. Rev. 239, 178-196 (2011)

L. Gelao, C. Criscitiello, A. Esposito, M. De Laurentiis, L. Fumagalli, M.A. Locatelli, I. Minchella, M. Santangelo, S. De Placido, A.
Goldhirsch, G. Curigliano, Dendritic cell-based vaccines: Clinical applications in breast cancer. Immunotherapy 6(3), 349-360 (2014)

F. Ghezzi, A. Cromi, S. Uccella, S. Giudici, M. Franchi, P. Bolis, Leftright asymmetry in pelvic lymph nodes distribution: Is there a rightside prevalence? Eur. J. Obstet. Gynecol. Reprod. Biol. 127(2), 236 239 (2006)

B. Godin, C. Chiappini, S. Srinivasan, J.F. Alexander, K. Yokoi, M. Ferrari, P. Decuzzi, X. Liu, Discoidal porous silicon particles: Fabrication and biodistribution in breast Cancer bearing mice. Adv. Funct. Mater. 22(20), 4225-4235 (2012)

M.S. Goldberg, Immunoengineering: How nanotechnology can enhance cancer immunotherapy. Cell 161(2), 201-204 (2015)

P.W. Kantoff, C.S. Higano, N.D. Shore, E.R. Berger, E.J. Small, D.F. Penson, C.H. Redfern, A.C. Ferrari, R. Dreicer, R.B. Sims, Y. Xu, M.W. Frohlich, P.F. Schellhammer, Sipuleucel-T immunotherapy for castration-resistant prostate cancer. N. Engl. J. Med. 363(5), 411-422 (2010)

K.L. Knutson, K. Schiffman, M.L. Disis, Immunization with a HER-2/ neu helper peptide vaccine generates HER-2/neu CD8 T-cell immunity in cancer patients. J. Clin. Invest. 107(4), 477-484 (2001)

R. Kuai, L.J. Ochyl, K.S. Bahjat, A. Schwendeman, J.J. Moon, Designer vaccine nanodiscs for personalized cancer immunotherapy. Nat. Mater. 16(4), 489-496 (2017)

S. Kumar, A.C. Anselmo, A. Banerjee, M. Zakrewsky, S. Mitragotri, Shape and size-dependent immune response to antigen-carrying nanoparticles. J. Control. Release 220(Pt A, 141-148 (2015)

A.W. Li, M.C. Sobral, S. Badrinath, Y. Choi, A. Graveline, A.G. Stafford, J.C. Weaver, M.O. Dellacherie, T.Y. Shih, O.A. Ali, J. Kim, K.W. Wucherpfennig, D.J. Mooney, A facile approach to enhance antigen response for personalized cancer vaccination. Nat. Mater. 17(6), $528-52+(2018)$

F. Lucchini, M.G. Sacco, N. Hu, A. Villa, J. Brown, L. Cesano, L. Mangiarini, G. Rindi, S. Kindl, F. Sessa, et al., Early and multifocal tumors in breast, salivary, harderian and epididymal tissues developed in MMTY-Neu transgenic mice. Cancer Lett. 64(3), 203-209 (1992)

M. Luo, H. Wang, Z. Wang, H. Cai, Z. Lu, Y. Li, M. Du, G. Huang, C. Wang, X. Chen, M.R. Porembka, J. Lea, A.E. Frankel, Y.X. Fu, Z.J. Chen, J. Gao, A STING-activating nanovaccine for cancer immunotherapy. Nat. Nanotechnol. 12(7), 648-654 (2017)

J. Mai, Y. Huang, C. Mu, G. Zhang, R. Xu, X. Guo, X. Xia, D.E. Volk, G.L. Lokesh, V. Thiviyanathan, D.G. Gorenstein, X. Liu, M. Ferrari, $\mathrm{H}$. Shen, Bone marrow endothelium-targeted therapeutics for metastatic breast cancer. J. Control. Release 187, 22-29 (2014)

E.A. Mittendorf, G.T. Clifton, J.P. Holmes, K.S. Clive, R. Patil, L.C. Benavides, J.D. Gates, A.K. Sears, A. Stojadinovic, S. Ponniah, G.E. Peoples, Clinical trial results of the HER-2/neu (E75) vaccine to prevent breast cancer recurrence in high-risk patients: From US military Cancer institute clinical trials group study I-01 and I-02. Cancer 118(10), 2594-2602 (2012)

G. Napolitani, A. Rinaldi, F. Bertoni, F. Sallusto, A. Lanzavecchia, Selected toll-like receptor agonist combinations synergistically trigger a $\mathrm{T}$ helper type 1-polarizing program in dendritic cells. Nat. Immunol. 6(8), 769-776 (2005)

H. Shen, J. You, G. Zhang, A. Ziemys, Q. Li, L. Bai, X. Deng, D.R. Erm, X. Liu, C. Li, M. Ferrari, Cooperative, nanoparticle-enabled thermal therapy of breast cancer. Adv Healthc Mater 1(1), 84-89 (2012)

H. Shen, C. Rodriguez-Aguayo, R. Xu, V. Gonzalez-Villasana, J. Mai, Y. Huang, G. Zhang, X. Guo, L. Bai, G. Qin, X. Deng, Q. Li, D.R. Erm, B. Aslan, X. Liu, J. Sakamoto, A. Chavez-Reyes, H.D. Han, A.K. Sood, M. Ferrari, G. Lopez-Berestein, Enhancing chemotherapy response with sustained EphA2 silencing using multistage vector delivery. Clin. Cancer Res. 19(7), 1806-1815 (2013a)

J. Shen, R. Xu, J. Mai, H.C. Kim, X. Guo, G. Qin, Y. Yang, J. Wolfram, C. Mu, X. Xia, J. Gu, X. Liu, Z.W. Mao, M. Ferrari, H. Shen, High 
capacity nanoporous silicon carrier for systemic delivery of gene silencing therapeutics. ACS Nano 7(11), 9867-9880 (2013b)

H. Shen, T. Sun, H.H. Hoang, J.S. Burchfield, G.F. Hamilton, E.A. Mittendorf, M. Ferrari, Enhancing cancer immunotherapy through nanotechnology-mediated tumor infiltration and activation of immune cells. Semin. Immunol 34, 114 (2017)

J.L. Tanyi, S. Bobisse, E. Ophir, S. Tuyaerts, A. Roberti, R. Genolet, P. Baumgartner, B.J. Stevenson, C. Iseli, D. Dangaj, B. Czerniecki, A. Semilietof, J. Racle, A. Michel, I. Xenarios, C. Chiang, D.S. Monos, D.A. Torigian, H.L. Nisenbaum, O. Michielin, C.H. June, B.L. Levine, D.J. Powell Jr., D. Gfeller, R. Mick, U. Dafni, V. Zoete, A. Harari, G. Coukos, L.E. Kandalaft, Personalized cancer vaccine effectively mobilizes antitumor $\mathrm{T}$ cell immunity in ovarian cancer. Sci. Transl. Med. 10(436), eaao5931 (2018)

M.E. Turnis, X.T. Song, A. Bear, A.E. Foster, S. Gottschalk, M.K. Brenner, S.Y. Chen, C.M. Rooney, IRAK-M removal counteracts dendritic cell vaccine deficits in migration and longevity. J. Immunol. 185(7), 4223-4232 (2010)

X. Xia, J. Mai, R. Xu, J.E. Perez, M.L. Guevara, Q. Shen, C. Mu, H.Y. Tung, D.B. Corry, S.E. Evans, X. Liu, M. Ferrari, Z. Zhang, X.C. Li, R.F. Wang, H. Shen, Porous silicon microparticle potentiates antitumor immunity by enhancing cross-presentation and inducing type I interferon response. Cell Rep. 11, 957-966 (2015)
R. Xu, Y. Huang, J. Mai, G. Zhang, X. Guo, X. Xia, E.J. Koay, G. Qin, D.R. Erm, Q. Li, X. Liu, M. Ferrari, H. Shen, Multistage vectored siRNA targeting ataxia-telangiectasia mutated for breast Cancer therapy. Small 9(9-10), 1799-1808 (2013)

R. Xu, G. Zhang, J. Mai, X. Deng, V. Segura-Ibarra, S. Wu, J. Shen, H. Liu, Z. Hu, L. Chen, Y. Huang, E. Koay, Y. Huang, J. Liu, J.E. Ensor, E. Blanco, X. Liu, M. Ferrari, H. Shen, An injectable nanoparticle generator enhances delivery of cancer therapeutics. Nat. Biotechnol. 34(4), 414-418 (2016)

O. Yoruk, R. Yuksel, Y. Yuksel, S. Dane, Left-right asymmetry in neck lymph nodes distribution in patients with bilateral laryngeal cancer. Surg. Radiol. Anat. 36(3), 239-242 (2014)

H. Zong, S. Sen, G. Zhang, C. Mu, Z.F. Albayati, D.G. Gorenstein, X. Liu, M. Ferrari, P.A. Crooks, G.J. Roboz, H. Shen, M.L. Guzman, In vivo targeting of leukemia stem cells by directing parthenolideloaded nanoparticles to the bone marrow niche. Leukemia 30(7), 1582-1586 (2016)

Publisher's note Springer Nature remains neutral with regard to jurisdictional claims in published maps and institutional affiliations. 